\title{
Epidemiological Survey of First Human Brucellosis Outbreak Caused by the Sika Deer (Cervus nippon) - Guizhou Province, China, 2019
}

\author{
Zhongfa Tao ${ }^{1,2,3,8 ;}$; Zhangping Yang ${ }^{4, \times<}$; Yishan Chen ${ }^{2.5}$; Shufeng Yang ${ }^{6}$; Jingchao $\mathrm{Xu}^{7}$; \\ Yue Wang'; Mingyu Lei ${ }^{1}$; Yun Gou'; Qiulan Chen ${ }^{2,3, * ;}$ Yan Huang ${ }^{1, *}$
}

\section{Summary}

What is already known on this topic?

Brucellosis is a zoonotic infectious disease caused by Brucella spp. The main source of infection in human brucellosis is sick animals, mainly including sheep, goat, and cattle, but sika deer (Cervus nippon) can also cause human brucellosis. The first human brucellosis case in Guizhou Province was reported in 2009, and no brucellosis outbreak was reported caused by sika deer ever before.

\section{What is added by this report?}

This is the first reported outbreak of human brucellosis caused by sika deer in Guizhou Province. Inappropriate regulation of animal movement may be the main driver of introducing and spreading brucellosis in southern areas. The ability to diagnose brucellosis in both humans and animals was weak in the county where the outbreak took place.

What are the implications for public health practice?

It was suggested to prioritize occupational protection and health education for sika deer breeders. The inspection of the movement of animals and the reimbursement policy need to be improved.

On June 24, 2019, 6 villagers from a sika deer (Cervus nippon) farm came to their local CDC for consultation about brucellosis. After onsite inquiry, three of the six villagers had repeated fever, joint pain, low back pain, and other symptoms. Three villagers tested positive for the Rose Bengal precipitation test (RBPT) for brucellosis. Two of the three villagers tested positive in the standard agglutinating test (SAT). According to the national diagnostic standard on human brucellosis (1), two were confirmed cases and one was a clinical case. Therefore, they were considered to be infected with human brucellosis, suspected coming from sika deer. Since sika deer were rarely reported as an infection source to human in southern provinces and even none in Guizhou Province before (2-3), the provincial CDC staff conducted an onsite epidemiological investigation to verify the outbreak and the infection source.

According to the earliest date of illness onset in the three cases, investigators reviewed the outpatient log of nearby hospitals with a period ranging from September 1, 2018 to June 28, 2019. This study also conducted interviews with a uniform questionnaire and used RBPT and SAT, to identify potential cases among farm workers, the family members of the patients, and other people who had contacted sika deer and other livestock in the village during this period. Lastly, one more clinical case was found according to the national diagnostic standard, making the total number of cases four (1). They were 3 males and 1 female breeders in the sika deer farm. None of the patients' family members and other villagers were found to have human brucellosis.

The earliest illness onset time of the patients was October 2018, while the latest onset time was February 2019 , and three patients out of the total four presented symptoms from October to November 2018. The 3 of them first visited the local people's hospital in October, December 2018, and February 2019, respectively, but all failed to be confirmed with human brucellosis (Figure 1). The blood samples of the patients were collected for bacteria cultivation in June 2019, but the results were negative due to the former history of antibacterial drug use before diagnosis.

The farm was separated from the village by a river and a mountain (Figure 1). Sika deer were introduced in two batches: the first batch was purchased from Guangxi Zhuang Autonomous Region in June 2016 with an inspection and quarantine certificate; the second batch was introduced in January 2018 from another township in the county without a quarantine certificate. The two batches of imported sika deer were 


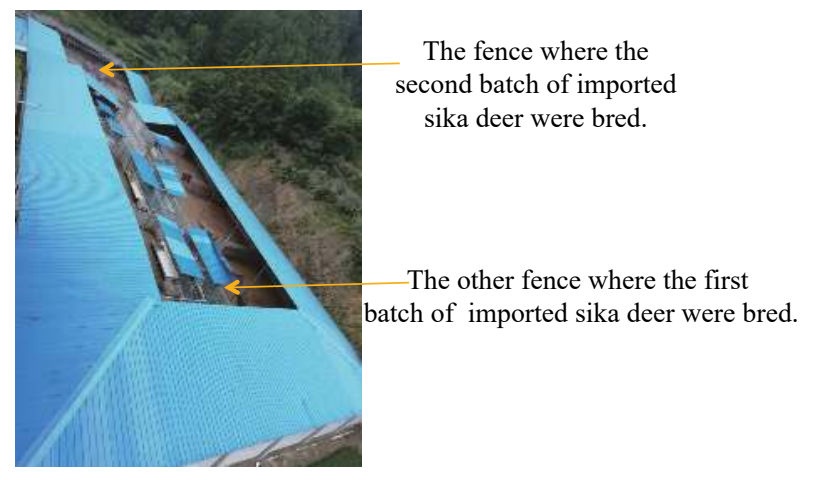

FIGURE 1. The farm where the sika deer were bred. Note: The farm was located at the foot of a mountain, which was separated from the village.

kept separately in different but adjacent fences. In May 2018, several sika deer began to suffer from leg suppuration, diarrhea, miscarriage, and even death.

A total of 7 staff were in the farm, and the incidence of human brucellosis in the farm was $57.1 \%$ (4/7). All staff had no history of contact with other livestock or other animals except for sika deer since June 2016. All denied ever drinking raw cow/goat milk or eating raw meat. During the breeding process, they had handled the abortion placenta of the sika deer by bare hands without wearing any personal protection equipment. A case-control study was conducted to determine the risk factors of infection, taking people who had contacted sika deer but not diagnosed as human brucellosis case as a control group and staff who had different exposed channels as case group. The study indicated that the regular feeding $(\mathrm{OR}=99,95 \% \mathrm{CI}: 1.6-6,053.1)$ and treatment of abortion placenta exposure $(\mathrm{OR}=99,95$ $\%$ CI: 1.6-6,053.1) were risk factors for the infection in this cluster (Table 1).

The local animal CDC collected 9 blood specimens of living sika deer from the first batch in the farm for Brucella antibody detection and cultivation but failed to have positive results. No specimen could be taken from the second batch of the sika deer, since the deer were all sold by the farm owner for the economic incentive soon after the farm staff were confirmed with brucellosis. Local health department disinfected the farm and educated the farm staff and the owner about the prevention measures of brucellosis. No sika deer were killed as the farm owner sold out all the sika deer at last for the reason of no reimbursement for the killed sick deer paid by the local government. The local animal CDC failed to trace the sika deer due to lack of ability to contact the buyer.

\section{DISCUSSION}

Human brucellosis is common zoonosis and is currently endemic in Asia, the Eastern Mediterranean Region, and the Caribbean Region and reemerges in developed countries with the rapidly increasing international travel and business (4-6). China faces an increasing burden of human brucellosis since the 21 st century (2-3). The majority of cases emerged in northern China, where husbandry is more developed, but the southern provinces were also increasing due to the movement of ill animals (7-8). The disease causes flu-like symptoms, including fever, weakness, malaise, and weight loss, which are easy to be neglected and misdiagnosed by patients and clinicians (9-10) . Delayed diagnosis was prone to cause chronic brucellosis, leading to great harm to the patients and their families (10). Brucellosis is caused by various Brucella species, which mainly infect cattle, swine, goats, sheep, and dogs (11). However, sika deer were reported to cause cases in humans both internationally and domestically (12-14). Humans become infected with Brucella species mainly by contact with sick animals and ingestion of contaminated milk and cheese (12). Having contact with the miscarriage material of sick animals is a common infection channel as Brucella is prone to be located at the genital tract of animals and cause animal miscarriage (15).

TABLE 1. The case study of controlled exposure of an outbreak of brucellosis in Guizhou Province, China, 2019*.

\begin{tabular}{|c|c|c|c|c|c|c|c|c|}
\hline \multirow{2}{*}{ Exposure pathway } & \multicolumn{2}{|c|}{ Case group } & \multicolumn{2}{|c|}{ Control group } & \multirow{2}{*}{$p$} & \multirow{2}{*}{ OR } & \multicolumn{2}{|c|}{$95 \% \mathrm{Cl}$} \\
\hline & Yes & No & Yes & No & & & Lower & Upper \\
\hline Breeding deer & 4 & 0 & 2 & 3 & 0.14 & 12.6 & 0.4 & 356.4 \\
\hline Regular feeding & 4 & 0 & 0 & 5 & 0.03 & 99 & 1.6 & $6,053.1$ \\
\hline Treatment of abortion placenta & 4 & 0 & 0 & 5 & 0.03 & 99 & 1.6 & $6,053.1$ \\
\hline Treatment of sick and dead sika deer & 3 & 1 & 1 & 4 & 0.12 & 12 & 0.5 & 280.1 \\
\hline Delivery & 2 & 2 & 0 & 5 & 0.16 & 11 & 0.4 & 324.5 \\
\hline
\end{tabular}

* Where zeros cause problems with computation of the odds or its standard error, 0.5 is added to all cells (a, b, c, d). 
Based on literature review and the results of the investigation, this cluster of human brucellosis was likely caused by sika deer. First, the sika deer of the farm had typical symptoms of animal brucellosis such as miscarriage before the patients become ill. Second, all four patients were staff of the sika deer farm. Except for breeding sika deer, no other epidemiological history of infection with brucellosis was detected. Third, the case-control study suggested that handling the abortion placenta of sika deer and regular breeding of sika deer were risk factors for infection.

This study was subject to some limitations. Neither serological nor etiological evidence of brucellosis for the sika deer was required. The negative test results of sika deer specimens in this investigation may be due to insufficient detection capabilities of the county-level animal CDC or sampling bias (that is, the samples collected were all from healthy sika deer). Delays in diagnosis were also a prominent problem in this event and were common in southern China, especially where no human brucellosis was reported before like in this county (2). It is important to strengthen the diagnostic ability of both local veterinarians and clinicians.

This was the first report of human brucellosis caused by deer in Guizhou Province. With the development of sika deer breeding industry in China, sika deer are increasingly a risk factor for human brucellosis. The occupational protection and health education of the sika deer breeders should be prioritized. In addition, illegal sales of sick animals were also found in this investigation. This phenomenon is the main driver of introducing and spreading brucellosis in southern areas. Consequently, the inspection of the movement of animals needs improvement, as does the reimbursement policy.

Acknowledgments: Staff of the Leishan County Center for Disease Control and Prevention; Village Committee of Datang Village; Datang Village Health Room.

Conflicts of interest: No conflicts of interest were reported.

\section{doi: $10.46234 / \mathrm{ccdcw} 2021.081$}

\# Corresponding authors: Qiulan Chen, Chenql@chinacdc.com; Yan Huang, cdchuangyan@163.com.

\footnotetext{
Guizhou Provincial Center for Disease Control and Prevention, Guiyang, Guizhou, China; ${ }^{2}$ Division of Infectious Disease, Key Laboratory of Surveillance and Early Warning on Infectious Disease, China Center for Disease Control and Prevention, Beijing, China; 3 China Field Epidemiology Training Project, Beijing, China; ${ }^{4}$ Qiandongnan Prefecture Center for Disease Control and Prevention,
}

Kaili,Guizhou, China; ${ }^{5}$ Emory University, America; ${ }^{6}$ Leishan County Center for Disease Control and Prevention, Leishan, Guizhou, China;

${ }^{7}$ Qiannan Prefecture Center for Disease Control and Prevention, Duyun, Guizhou, China.

\& Joint first authors.

Submitted: November 03, 2020; Accepted: March 23, 2021

\section{REFERENCES}

1. National Health Commission of the People's Republic of China. WS 269-2019 Diagnosis for brucellosis. Beijing: China Standards Press, 2019. (In Chinese).

2. Shang DQ, Xiao DL, Yin JM. Epidemiology and control of brucellosis in China. Vet Microbiol 2002;90(1 - 4):165 - 82. http://dx.doi.org/ 10.1016/s0378-1135(02)00252-3.

3. Lai SJ, Zhou H, Xiong WY, Yu HJ, Huang ZJ, Yu JX, et al. Changing epidemiology of human brucellosis, China, 1955-2014. Emerg Infect Dis 2017;23(2):184 - 94. http://dx.doi.org/10.3201/eid2302.151710.

4. Franc KA, Krecek RC, Häsler BN, Arenas-Gamboa AM. Brucellosis remains a neglected disease in the developing world: a call for interdisciplinary action. BMC Public Health 2018;18:125. http://dx. doi.org/10.1186/s12889-017-5016-y.

5. Dean AS, Crump L, Greter H, Schelling E, Zinsstag J. Global burden of human brucellosis: a systematic review of disease frequency. PLoS Negl Trop Dis 2012;6(10):e1865. http://dx.doi.org/10.1371/journal. pntd.0001865.

6. Pappas G, Papadimitriou P, Akritidis N, Christou L, Tsianos EV. The new global map of human brucellosis. Lancet Infect Dis 2006;6(2):91 9. http://dx.doi.org/10.1016/S1473-3099(06)70382-6.

7. Chen ZL, Zhang WY, Ke YH, Wang YF, Tian BL, Wang DL, et al. High-risk regions of human brucellosis in China: implications for prevention and early diagnosis of travel-related infections. Clin Infect Dis 2013;57(2):330 - 2. http://dx.doi.org/10.1093/cid/cit251.

8. Shi YJ, Lai SJ, Chen QL, Mou D, Li Y, Li XX, et al. Analysis on the epidemiological features of human brucellosis in northern and southern areas of China, 2015-2016. Chin J Epidemiol 2017;38(4):435 - 40. http://dx.doi.org/10.3760/cma.j.issn.0254-6450.2017.04.005. (In Chinese).

9. Zheng RJ, Xie SS, Lu XB, Sun LH, Zhou Y, Zhang YX, et al. A systematic review and meta-analysis of epidemiology and clinical manifestations of human brucellosis in China. Biomed Res Int 2018;2018:5712920. http://dx.doi.org/10.1155/2018/5712920.

10. Dean AS, Crump L, Greter H, Hattendorf J, Schelling E, Zinsstag J. Clinical manifestations of human brucellosis: a systematic review and meta-analysis. PLoS Negl Trop Dis 2012;6(12):e1929. http://dx. doi.org/10.1371/journal.pntd.0001929.

11. World Health Organization. Brucellosis. 2020. https://www.who.int/ news-room/fact-sheets/detail/brucellosis. [2021-1-17].

12. Franco MP, Mulder M, Gilman RH, Smits HL. Human brucellosis. Lancet Infect Dis 2007;7(12):775 - 86. http://dx.doi.org/10.1016/ S1473-3099(07)70286-4.

13. Cui BY, Li JY, Yin JM, Li YK, Liang ZH. Epidemiological survey of brucellosis in a deer farm in Shanxi Province. Chin J Epidemiol 2004; 25(2):172. https://kns.cnki.net/kcms/detail/detail.aspx?FileName= ZHLX200402027\&DbNameCJFQ2004. (In Chinese).

14. He YP, Wang DL. Survey of deer as a source of infection in brucellosis. Chin J Endemiol Prev 1998;13(5):278-80. https://kns.cnki.net/ $\mathrm{kcms} /$ detail/detail.aspx?FileName=DYBF199805012\&DbNameCJFQ1 998. (In Chinese).

15. Musallam II, Abo-Shehada MN, Hegazy YM, Holt HR, Guitian FJ. Systematic review of brucellosis in the Middle East: disease frequency in ruminants and humans and risk factors for human infection. Epidemiol Infect 2016;144(4):671 - 85. http://dx.doi.org/10.1017/S095026881 5002575. 